\title{
O que é a palavra? Reflexões sobre a herança gramatical greco-latina
}

\author{
Maria João Marçalo* \\ "Los hechos (en nuestro caso, los datos grammaticales) \\ son como son y no los afecta el nombre con que los \\ reconozcamos"
}

Alarcos LLorach

RESUMO: Analisamos a concepção de PALAVRA herdada da tradição greco-latina. Revisamos ainda algumas ideias linguísticas de autores dos séculos XIX e XX (Vendryes, Saussure) e abordamos o modo como os primeiros gramáticos portugueses tratara m esta questão (João de Barros, Melo Bacelar, Lobato).

PALAVRAS-CHAVE: Ideias linguísticas; palavra; morfologia; sintaxe; português.

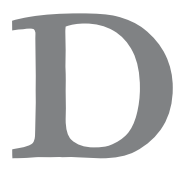

efinir com exactidão o objecto da sintaxe não é tarefa fácil, tal como não o é definir o objecto da morfologia. Subjaz a esta questão uma outra: qual é o tipo de relação existente entre ambas? Tal como R.H. Robins, ${ }^{1}$ pensamos que a resposta a tal pergunta está intrinsecamente relacionada com a resposta que dermos a uma terceira interrogação: entre que tipos de unidades linguísticas se estabelecem as relações sintácticas?

* Universidade de Évora, Portugal-mjm@uevora.pt.

1 Ver Robins, 1961, p. 386-395. 


\section{MARÇALO, Maria João. O que é a palavra? Reflexões sobre a herança gramatical greco-latina}

Tradicionalmente, as relações sintácticas estabelecem-se entre palavras, sendo considerada do âmbito da morfologia a problemática relativa às relações desenvolvidas no interior das palavras.

Neste breve excurso tocamos uma das questões que mais rios de tinta tem feito correr entre linguistas. Como definir palavra?

Não podemos, nem queremos, fazer tábua rasa de toda uma tradição que nos precede e certamente nos influencia e condiciona, ${ }^{2}$ pois, como bem afirma Guy Serbat, "L'importance de la tradition gréco-latine est telle qu'on ne peutpas se dispenser sans risque de se reporter à elle, afin de mettre à nu les postulats et le méthodes qui fondent nos raisonnements" (1981, p. 9). Assim sendo, não é dispensável traçar um breve percurso pela história das ideias linguísticas de modo a que se torne visível o fio condutor das opções teóricas que demonstre de que modo elas se filiam ou afastam de um labor de milénios desenvolvido a partir da tradição greco-latina.

\section{A herança gramatical greco-latina}

A reflexão inicial sobre a linguagem é nitidamente marcada pelos domínios onde se desenvolve, nomeadamente pela filosofia, pela retórica e pela crítica literária e textual. ${ }^{3}$

Da oposição nome/verbo de Platão, ${ }^{4}$ passando pelas considerações de ordem fonética presentes na Poética de Aristóteles e o estabelecimento das partes do discurso feito pelos estóicos, percorre-se um longo caminho até ao aparecimento no século I a.C. do que se considera ser a primeira gramática: a Technè Grammatike atribuída a Dionísio de Trácia. ${ }^{5}$

$\mathrm{Na}$ tradição alexandrina, a gramática, distinta do labor filológico, define-se como "un savoir portant sur l'essentiel de ce qui est chę les poètes et les écrivains (les prosateurs)" e as suas partes concernem à prosódia, à interpretação das questões poéticas, à explicação das palavras raras e dos mitos, à análise etimológica, ao estabelecimento da analogia e à crítica dos poemas. A Technè e

2 "Il n'est guère de science qui prétende se créer ex nibilo en faisant table rase des acquis de son passê" (Pergnier, 1986, p. 5).

3 Dado que estas questões nos ocuparão aqui de um modo meramente marginal, aconselha-se entre outras, as seguintes obras para o aprofundamento desta temática: Marc Baratin e Françoise Desbordes (1981); Sylvain Auroux et al (1984); Sylvain Auroux (dir.) (1992); M Helena de Moura Neves (1987).

4 Platão quer no Crátilo quer no Sofista, opõe duas partes do discurso: nome/ verbo ou sujeito/ predicado, Aristóteles em Da Interpretação segue o modelo platónico.

5 Ver Jean Lallot (1989). 
De Lingua Latina de Varrão são, pois, as primeiras reflexões que consideram a língua em si mesma objecto de descrição.

Dos 25 livros de De Lingua Latina, de Varrão, datados de meados do século I a.C., só se conhecem hoje os livros V a X. Contrariamente ao que seria de esperar em termos cronológicos, Varrão não classifica as palavras em oito categorias, oscilando entre duas a quatro, uma vez que considera que as diferentes categorias de palavras são uma construção teórica que depende do ponto de vista e dos critérios de cada autor. ${ }^{7}$ Varrão vê a palavra como uma espécie de átomo da língua, átomo esse que apresenta formas variáveis. Para Varrão a palavra é uma construção abstracta, a unidade invariante de um dado número de formas variáveis.

No século segundo da nossa era, das mãos de um outro alexandrino, herdamos uma primeira obra intitulada Sintaxe. ${ }^{8} \mathrm{O}$ seu autor, Apolónio, apelidado de Díscolo (difícil), oferece-nos uma análise "técnica" (tal como Dionísio de Trácia) que se debruça sobre a língua, por oposição à análise do "gramático" (filólogo) que se ocupava primordialmente em editar os textos de um corpus escrito. ${ }^{9}$

Se partirmos de uma perspectiva cronológica, concluimos que a morfologia foi formalizada antes da sintaxe, ou seja, a descrição morfológica do grego precede em dois séculos a sua descrição sintáctica.

As bases conceptuais da descrição linguística da Antiguidade Ocidental estruturam-se a partir do modelo da palavra e do paradigma. ${ }^{10}$ Uma gramática que, ao basear-se na palavra, implica a sua identificação como unidade linguística, postula um conjunto de classes de palavras e estuda as relações entre as palavras na construção de frases.

A Technè, modelo dos estudos gramaticais durante séculos, estabelece como unidade básica da descrição a lexis - palavra, e como unidade superior o

\footnotetext{
Marc Baratin e Françoise Desbordes, idem, p. 34.

Baratin e Desbordes afirmam: "lidée relativement simple de classes paradigmatiques dont chaque élément aurait les mêmes valences syntaxiques, ne peut être appliquée qu'a grands renforts d'exceptions et d'interférences" (Ibidem, p. 40).

8 Consultámos a edição de Vicente Bécares Botas (1987).

9 Ver Jean Lallot (1996).

10 Despite the richness of classical morphology, a theory of the morpheme was not achieved and classical grammatical statements exbibit the strenghts and the weaknesses of a word based morphology (R. H. Robins, 1990, p. 29). Sobre o modelo "palavra e paradigma" veja-se o artigo publicado em 1954, na revista Word por Charles Hockett, "Two models of grammatical description", também inserido em Martin Joos (ed.), 1966, p. 386-389.
} 
logos - frase. As oito classes de palavras propostas, com uma pequena alteração concernente à inexistência do artigo em latim, mantiveram-se constantes nas descrições gramaticais do grego e do latim evidenciando ainda hoje uma influência notável nas descrições das línguas modernas europeias. ${ }^{11}$

A gramática permaneceu a base do ensino na Idade Média. As línguas vernaculares, e por seu intermédio as línguas dos povos "descobertos" no Novo Mundo, são alvo de uma gramatização de base latina, idioma que se mantém a língua de cultura por excelência a par da crescente valorização dos vernáculos.

A terminologia gramatical directamente transposta da língua latina para as diferentes línguas europeias explica a relativa opacidade e comunhão de designações de conceitos gramaticais que ainda hoje se pode observar na chamada gramática tradicional.

O próprio conteúdo das descrições gramaticais é relativamente estável: aborda-se, de modo opcional, a fonética e a ortografia, e de modo quase constante as partes do discurso, a etimologia, num sentido próximo do que actualmente se engloba na morfologia (designação que se impõe somente a partir do século XVIII) - acidentes da palavra, derivação e composição e que até ao século XIII teve a designação generalizada de analogia; a sintaxe, tratada normalmente de modo sucinto, onde são afloradas as questões relativas à concordância e regime, e ainda uma parte dedicada às figuras de retórica.

Em termos teóricos, a categorização das unidades e a sua identificação na cadeia falada, representa já um determinado posicionamento epistemológico face à língua. A gramática, longe de ser uma mera descrição de uma língua natural, é um instrumento heurístico, ${ }^{12}$ uma ferramenta que permite reconhecer e identificar um sistema de regras e formas que não estão acessíveis na competência de um mesmo locutor, mas apenas na dimensão comunitária intrínseca ao objecto língua. ${ }^{13}$

Os gramáticos bizantinos, que seguem sem rupturas dignas de menção, os seus antecessores helénicos e áticos, dos quais destacámos Dionísio de

11 Ver Maria Helena de Moura Neves, op. cit., nota 2.

12 De même que la lunette astronomique a permis à Galilée d'observer les montagnes de la lune, la grammaire latine (interiorisée dès l'enfance) permettra aux premiers grammairiens des vernaculaires de voir les phénomènes de leur propre langue, à ceci prèsque, contrairement à l'observatoire que forme la grammaire latine, rien de la lentille de la lunette, ne peut confondre avec les proprietés de l'objet quelle permet d'observer, S. Auroux, "Le développement de la grammaire occidentale", 1992, v. 2, p. 37.

13 Na linha martinetiana, concebemos a língua como um instrumento de comunicação duplamente articulado, variável de comunidade para comunidade. Cf. André Martinet, 1985, p. 24. 
Trácia e, três séculos depois Apolónio Díscolo, são erigidos em modelos que pautam as obras gramaticais posteriores. Também em Bizâncio, à época designada Constantinopla, publicam-se cerca do ano 500 d. C. as Intitutiones Grammaticae do gramático latino Prisciano.

Prisciano, na linha de Apolónio, traça um paralelo entre a ordem necessária às letras / sons no interior da palavra e a ordem necessária às palavras no interior da frase. Prisciano representa, nas palavras de Bertil Malmberg, o cume da ciência gramatical latina. ${ }^{14}$ Tendo sido professor em Constantinopla, preocupa-se sobretudo em verter para o latim todos os ensinamentos herdados da Technè e da Sintaxe de Apolónio, facto que ele próprio menciona não só na introdução como ao longo da sua obra, ao considerar Apolónio e o seu filho Herodiano as grandes autoridades em gramática.

\section{Mere logou / Partes orationis}

Após este brevíssimo excurso pelos nomes e obras que mais influenciaram a tradição gramatical europeia e sem querer fazer aqui história da linguística ou das ideias linguísticas, desloquemo-nos directamente ao ponto que nos levou a viajar no tempo, ou seja, tentar encontrar a resposta para a questão que inicialmente colocámos relativamente aos tipos de unidades linguísticas.

Apercebemo-nos que esta problemática das partes do discurso ou classes de palavras é em simultâneo uma velha e uma nova questão, ou se preferirmos, uma temática da tradição mas ao mesmo tempo uma temática que se posiciona novamente no centro da actualidade linguística.

Deter-nos-emos por isso naquilo que na tradição consideramos ser determinante para as problemáticas actuais e que de modo algum poderá ser ignorado sob pena de descartarmos como ultrapassadas as premissas que conformam as próprias bases do nosso questionamento teórico. ${ }^{15}$ Pensamos, com Georges Mounin, que devemos "iluminar com luz sempre actual os condicionalismos próprios das pesquisas de hoje em dia, porque também nós, no decorrer do trabalho estamos sempre dentro da bistória". Acreditamos ainda

14 Cf. Bertil Malmberg, 1991, p. 97.

15 Concordamos inteiramente com Manuel Saraiva Barreto quando escreve: "urge atentar no papel que aqueles mesmos gregos desempenharam na formulação e reflexão dos legítimos problemas fundamentais que preenchem uma larga e substancial gama dos grandes tópicos da Linguística actual.” (1970, p. 2-3). 
que o conhecimento do pensamento linguístico de que somos herdeiros permitirá, como refere também Mounin, "uma mais completa formação do novel linguista", facultando uma visão de conjunto do quadro das investigações sobre os princípios e os métodos" e "uma mais completa inteligência dos problemas através do conhecimento do seu passado". ${ }^{16}$

A dicotomia lèxis/lógos está presente na República de Platão e também na Retórica e na Poética de Aristóteles. Nestas obras, a lèxis refere-se à forma de expressão que se opõe ao conteúdo expresso - lógos.

No decorrer da História, o valor semântico deste par lèxis/lógos evoluiu e com os estóicos, fazendo fé nos escritos de Diógenes Laércio, a lèxis é apenas "a voz articulada que pode ser anotada através de letras", sendo logos "a voz dotada de sentido emitida pelo pensamento". ${ }^{17}$ Como sublinha Lallot $(1989,121)$ "on voit qu'à un parallélisme fond-forme (Platon, Aristote) a tendue à se substituer, pour le couple lògos-lèxis, une polarité opposant le complexe - logos "jugement, énoncé, phrase" - au simple - lèxis "mot"." ${ }^{18}$

$\mathrm{Na}$ doutrina das "partes da frase" - méros lógou $u^{19}$-, a Gramática de Dionísio de Trácia desempenha um papel principal. No capítulo undécimo, muito breve e sintético como a própria obra na sua globalidade, diz-se:

$$
\begin{aligned}
& \text { Le mot (léxis) est la plus petite partie de la phrase (lógos) construite. } \\
& \text { La phrase est une composition en prose qui manifeste une pensée complète. } \\
& \text { La phrase a huit parties: le nom, le verbe, le participe, l'article, le pronom, la } \\
& \text { préposition, l'adverbe, la conjunction. (ibidem, 49). }
\end{aligned}
$$

São efectivamente as partes do discurso ou classes de palavras, que aqui nos interessam. Esta é uma questão que com certa regularidade se inscreve no centro da actualidade linguística. ${ }^{20}$

16 Cf. Georges Mounin, 1970, p. 11 e p. 16.

17 Ap. Jean Lallot, 1989, op. cit., p. 119.

18 Para uma apreciação mai completa do aspecto altamente polissémico deste par lògos-lèxis, ver idem, ibidem, notas referentes ao capítulo 11 da Technè, p. 119-125.

19 The term méros lógou, whence the modern "part of speech", recurs in the listing of the different grammatical classes of words. It had been first used by Plato, so far as is known, where it stands for constituents of the sentence; only with the growth in the numbers of classes of words distinguished by the Greek linguists did the expression take on its later meaning of "word class. R. Robins, op. cit., p. 38. Marc Baratin (1989, p. 27 e 41) traduz méros logou por “constituant d'énonce", porém, segundo Lallot (op. cit., p. 233), a partir da obra de Apolónio, méros lógou nunca se poderá aplicar a uma proposição, restringindo-se o seu significado aos elementos constitutivos da frase.

20 Veja-se a obra relativamente recente de L. Basset e M. Perennec (dir.) (1994). 


\section{Problemática das partes do discurso e unidades da língua}

Aquilo que podemos apelidar de esquema canónico das partes da oração, ou seja, a divisão em oito partes, que, como já afirmámos, se faz remontar a Dionísio Trácio, não se encontra, por exemplo na teoria varroniana. Varrão, cujos escritos datam do século I a.C., uma época em que as oito categorias de palavras deveriam estar estabelecidas, faz oscilar a divisão das partes orationis entre duas, três ou quatro categorias. ${ }^{21}$ Tal discrepância traduz já, em nosso entender, a dificuldade, que se mantém actual, de traçar fronteiras nítidas para as diferentes classes de palavras e para as próprias unidades que as constituem.

O número oito nem sempre é acolhido por todos, alternando, geralmente, com nove ou dez como assinala Emílio Aquiles Monteverde no século XIX, ao tratar da "classificação de palavras", usando o velho método de ensino de pergunta/resposta:

P. Quantas especies de palavras ha na lingua portugueza?

R. Os grammaticos não são concordes quanto ao seu numero, visto pretenderem uns que são oito, outros nove, outros dez, etc.; adoptando porém a opinião mais geralmente seguida, diremos que são oito, a saber: nome, artigo, pronome, verbo, adverbio, preposição, conjunção e interjeição. ${ }^{22}$

Corroboramos inteiramente as ideias de Marc Baratin e Françoise Desbordes quando afirmam: "Si l'on veut bien se demander ce qu'est un nom, un pronom, un verbe, etc., on verra qu'il n'y a pas de réponse précise et définitive. Cela revient à dire que la théorie des catégories de mots est, aujourd'bui encore, imparfaite" (1981, p. 40).

Não obstante tais incertezas, em certas épocas da historiografia linguística, o domínio da competência do gramático fica reduzido precisamente ao estudo das partes do discurso, e é de facto o que encontramos na Ars Minor

21 Cf. Louis Holtz, "Les parties du discours vues par les latins”, In L. Basset e M. Perenecc (dir.) (1994, p. 73-920. Robins considera Varrão o mais independente e original dos gramáticos latinos. Ver op. cit., p. 60.

22 Emílio Aquiles Monteverde publicou em 1833 Elementos de grammatica portugueza, desenvolvidos com a maior clareza possivivel para uso das aulas, Lisboa. A citação que fazemos é no entanto extraída do seu Manual encyclopedico para uso das Escolas de Instrução Primária, onde a par da gramática portuguesa (p. 43-118), se dão noções de aritmética, princípios gerais de moral, noções de civilidade, etc. A edição por nós consultada é a duodécima e data de 1886 (p. 44). 
de Donato. Esta obra em forma de diálogo, datando do século IV d.C., é um tratado sobre as partes do discurso. ${ }^{23}$

Os nomes latinos da oito partes do discurso aparecem, ao que se sabe, pela primeira vez no século I d.C., na Institutio Oratoria de Quintiliano, discípulo de Remmius Palaemon, porém Quintiliano refere-se-lhes como noções tradicionais e não recentes, o que permite inferir que a questão não era nova, mas, pelo contrário havia sido durante um período largo de tempo, alvo das mais variadas discussões entre alexandrinos e posteriormente entre latinos.

Quer usemos o texto latino de Prisciano $24 "$ Dictio est pars minima orationis constructae. Oratio est ordinatio dictionum congrua, sententiam perfectam demonstrans", quer remontemos à Téchné, ao enunciado no capítulo décimo primeiro, por nós citado anteriormente, encontramos como unidade linguística básica o que, usando a expressão corrente, designaremos palavra.

Esta problemática das partes do discurso ou classes de palavras, só nos últimos dez anos fez vir a lume várias obras cujos títulos são precisamente reveladores da actualidade do tema no horizonte da moderna linguística e de entre os quais destacamos, como meros exemplos: Mots et Parties du Discours, Les Parties du Discours, Les Classes de Mots. ${ }^{25}$ Cremos que simultaneamente esta prolixidade de títulos é reveladora da coexistência de pontos de vista que se por vezes se mostram consensuais, na sua maioria se afirmam diferentes ou até antagónicos.

A unidade linguística básica também continua a ser alvo de atenções se atendermos aos títulos que lhe são dedicados, dos quais destacamos, como meramente ilustrativo do que afirmámos, o livro de Jiri Kramsky The Word as a Linguistic Unit.

Se atentarmos no posicionamento da linguística do século XX face à palavra e às tradicionais classes de palavras, facilmente concluimos que a apreciação é globalmente negativa. Aponta-se principalmente a pluralidade e heterogeneidade de critérios, onde frequentemente critérios morfológicos, semânticos e sintácticos se entrecruzam.

\section{A linguística do século XX, a palavra e as partes do discurso}

Otto Jespersen, por exemplo, afirma:

23 Para um estudo aprofundado, ver L. Holtz (1981).

24 Ap. R. Robins, op. cit., p. 72, nota 36.

25 Cf. Pierre Swiggers et Willy Van Hoecke (dir.) (1986); Bernard Colombat (dir) (1988); Louis Basset e Marcel Pérennec (dir) (1994). 
quand on enseigne la grammaire, on a l'habitude de commencer par ranger les mots dans des classes, que l'on nomme généralement "parties du discours"....mais les définitions qu'on en donne sont loin d'avoir atteint le degré d'exactitude que l'on rencontre dans la géometrie euclidienne. (1971, 1924, p. 67). ${ }^{26}$

\section{Ferdinand de Saussure interroga-se:}

soit par exemple la distinction des parties du discours: sur quoi repose la classification des mots en substantifs, adjectifs, etc? Se fait-elle au nom d'un principe purement logique, extra-linguistique, appliqué du dehors sur la grammaire comme les degrés de longitude et de latitude sur le globe terrestre? Ou bien correspond-elle à quelque chose qui ait sa place dans le système de la langue et soit conditionné par lui ? (1972, 1916, p. 152).

Joseph Vendryès, a propósito da definição de palavra, escreve em 1914:

La variété des procédés morphologiques fait que la définition du mot varie suivant les langues", e conclui o capítulo dedicado às palavras e morfemas dizendo: "Le mot ne comporte donc pas de définition générale applicable à toutes les langues, si ce n'est celle qu'a proposée M. Meillet, et qui laisse précisément indécise la façon dont s'exprime l'emploi grammatical: "Un mot résulte de l'association d'un sens donné à un ensemble donné de sons susceptible d'un emploi grammatical donné. (1969, 1920, p. 106 e 108).

No capítulo III, dedicado às diferentes espécies de palavras, constata: "La difficulté de classer les parties du discours est telle qu'on n'estpas arrivé jusqu'ici à une classification satisfaisante" (ibidem, p. 134).

Lucien Tesnière crítica de modo acutilante as tradicionais partes do discurso:

La syntaxe traditionnelle distingue dix espéces de mots, qu'elle appelle les parties du discours et qu'elle retrouve plus ou moins dans la plupart des langues...Cette classification que repose sur un empirisme vague et stérile et non sur une doctrine précise et féconde, ne résiste pas à l'examen. (1982, 1959, p. 51-52).

Os linguistas não-europeus, como Leonard Bloomfield, por exemplo, também se ocupam desta matéria. Em Language escreve:

The term parts of speech is traditionally applied to the most inclusive and fundamental word-classes of a language, and then, in accordance with the principle

26 Mais tarde Hjelmslev escreve apropósito desta posição de Jespersen: "Como es sabido, Jespersen, aunque escéptico respecto al sistema tradicional de las partes de la oración, se ha resignado a mantenerlo en la terminología y en la práctica” (1976, p. 135). 
just stated, the syntactic form-classes are described in terms of the parts of speech that appear in them. However, it is impossible to set up a fully consistent scheme of parts of speech, because the word-classes overlap and cross each other. (1984, 1933, p. 196).

No dealbar de um novo milénio, e percorridos vários séculos de discussão sobre o tema, uma única conclusão nos parece justa - o debate sobre as partes do discurso e a noção de palavra está longe de se encerrar. Parecenos, contudo, que apesar de todas as críticas e defeitos que se lhes possam apontar, os conceitos de partes do discurso e de palavra devem ser valorizados enquanto instrumentos heurísticos. Se preferirmos usar a terminologia de Lagarde (1988, p. 106), diremos que tais conceitos devem ser valorizados na sua "funcionalidade epistemológica".

\section{As divisões ou partes da gramática}

A concepção (ou concepções) da obra gramatical dá-nos certamente pistas para entendermos a elaboração e evolução das diferentes disciplinas que na moderna linguística lidam com as línguas. Como já apontámos anteriormente, as nossas interrogações prendem-se sobretudo com as definições de morfologia e sintaxe.

Parece-nos lícito olhar as diferentes divisões que ao longo dos séculos têm sido feitas da gramática para daí tentarmos inferir os fundamentos das ideias que actualmente se discutem a propósito dessas duas disciplinas e do seu âmbito de estudos.

Sem visarmos à exaustividade, percorremos de modo bastante aleatório algumas gramáticas, dando particular atenção às de autores portugueses, a fim de descobrir as concepções mais ou menos alteradas que chegaram até nós, herdadas, como não poderia deixar de ser, da tradição greco-latina.

\section{A divisão quadripartida da gramática}

Se atentarmos nas palavras de João de Barros, vemos que no século XVI, a gramática do português se divide em quatro partes. Tal como os latinos "pártem a gramática em quatro partes", assim nós, à imitação deles " por termos as suas pártes", devemos, "usando dos termos da Gramática latina cujos filhos nós somos, por nam degenerar déla", dividir a gramática em "Ortografia, que tráta de lêtera; em Prosódia que tráta de sílaba; em Etimologia, que trata da diçam, e em Sintáxis a que responde a construçám” (1971, p. 294). 
Apesar de encontrarmos autores que distinguem só três partes, como Bernardo de Lima e Melo Bacelar (1783) ou duas partes, como por exemplo, António José dos Reis Lobato (1771), poderemos concluir que a divisão em quatro partes se impôs na Gramática se não até ao presente, ${ }^{27}$ pelo menos até fins do século XIX.

\section{Morfologia}

Já no último quartel do século XIX, mais precisamente em 1876, na Grammatica portugueza elementar, fundada sobre o methodo historico-comparativo, Teófilo Braga, escreve, qual arauto de ideias inovadoras: "para divisão fundamental da grammatica, as bases geraes por onde se analysa qualquer lingua - os Sons, as Formas e as Construções - rejeitamos essas velhas categorias irracionais de Etymologia, Syntaxe, Prosodia e Orthografia” (p. IX). Segundo indica, segue Brachet, na sua aplicação ao francês dos novos processos, nomeadamente na distinção de um ramo novo - a morfologia. A esse propósito afirma:

o estudo das palavras em quanto às suas flexões, formação por composição ou derivação, que se tratava imperfeitamente na chamada Etymologia, constitue um ramo novo, limitado ao estudo das formas ou Morphologia; a Etymologia toma um sentido restricto e único, o da derivação histórica da palavra. (idem, ibidem).

A gramática de Teófilo Braga divide-se, consequentemente, em três partes, a saber, Fonologia, Morfologia e Sintaxe. ${ }^{28}$

Procurámos ainda averiguar a partir de quando o vocábulo morfologia aparece registado nos dicionários portugueses. No Dicionário da Lingua Portuguesa, composto pelo Padre Rafael Bluteau reformado e accrescentado por António de Morais Silva, de 1789, não consta "morfologia". Só na $6^{a}$ edição, datada de 1858, nos aparece "Morphologia - História das formas de que a matéria pode ser revestida". Porém para encontrarmos uma referência ao domínio da gramática é preciso aguardar pela $8^{a}$ edição, de 1891, onde podemos ler, além do que integrava a $6^{a}$ edição, o seguinte: "A formação e transformação das palavras; o estudo d'esta parte da linguística".

27 Num estudo sobre as gramáticas do castelhano, António Ramajo Cano chega a idêntica conclusão. Cf. 1987, p. 36.

28 "Chama-se Grammatica de uma lingua a constituição regular e systematica da produção dos seus sons (phonologia), da formação das suas palavras (Morphologia) e da reunião d'ellas em phrases ou construcções (syntaxe)" (p. 1, op. cit.). 
Na edição de 1871 do Grande Dicionário Portuguez, on Thesouro da Lingua Portugueza de Frei Domingos Vieira, apenas se encontra "Morphologia - História das formas que pode tomar a matéria".

Consultado ainda o Diccionário da Lingua Portuguêsa de Cândido de Figueiredo, datado de 1899, vemos que já aí aparece também a referência ao sentido de "morfologia" como parte da gramática.

Talvez possamos concluir que o nascimento da morfologia como disciplina que se ocupa de factos da linguagem se situa, em Portugal, na segunda metade do século XIX.

Em sentido lato, diremos que a parte da gramática que em finais do século XIX é designada morfologia, fora inicialmente e até ao século XIII designada por analogia, sendo seu objecto de estudo a vox ou dictio (pars minima orationes constructae). Ao que sabemos, só em finais do século XIII, no Catholicon, Johanes de Balbis de Janua introduz o termo Etimologia, pelo qual se entende "o estudo das oito partes da oração e dos seus acidentes". ${ }^{29}$

\section{A Sintaxe}

Apesar do termo sýntaxis ter sido usado por Dionísio de Trácia e em parte a análise sintáctica estar pressuposta em algumas da considerações da Téchne, só no século II d.C. temos uma extensa obra dedicada à sintaxe e que já tivemos oportunidade de mencionar anteriormente: a Sintaxe da autoria de Apolónio. Nas palavras de Robins, "despite the earlier writings on Greek syntax this was the first attempt at a comprehensive syntactic description and analysis of the Greek language" (1990, p. 42). Apolónio usou as oito partes do discurso preconizadas por Dionísio, mas redefiniu algumas delas, baseando as suas descrições essencialmente no significado (énnois) em detrimento da forma (schema). ${ }^{30} \mathrm{~A}$ sua descrição sintáctica baseia-se nas relações entre o nome e o verbo e entre estes e as restantes categorias. Prisciano, grande admirador de Apolónio e do seu filho Herodiano, dedica os últimos dois livros dos dezoito que constituem as Institutio Grammaticae à constructio, a qual, segundo ele os gregos denominam sintaxe. ${ }^{31}$ A gramática organiza-se em torno dos constituintes do enuncia-

29 Ver a Introdução de Miguel Ángel Esparza e Ramón Sarmiento a Nebrija, Gramática Castellana.

30 Cf. Robins, op. cit., p. 42.

31 Para uma correcta e aturada apreciação das teorias sintácticas da Antiguidade, remetemos para o cuidadoso estudo de Marc Baratin (1989). 
do, sendo considerados dois níveis em relação a tais elementos. Num nível inferior, as letras e as sílabas, enquanto componentes dos mesmos. No nível superior a combinação desses constituintes, ou partes do discurso - a constructio (Baratin, 1989, p. 368).

As gramáticas das línguas vernáculas, evidenciando uma organização formal e sistemática originária da análise do latim, definem a sintaxe de um modo semelhante ao de Prisciano. Para nos limitarmos à Península Ibérica, referiremos Nebrija, que, ao tratar das partes da gramática, afirma: "La cuarta (parte da gramática) los griegos llamaron sintaxis, los latinos construcción, nosotros podemos la llamar orden; a esta pertenece ordenar entre si las palabras i partes de la oracion" (1492, 1992, p. 113). Fernão de Oliveira fala da construição, nome dado pelos gramáticos à "composição ou concerto que as partes ou dicções da nossa língua têm entre si" (1536, 1975, p. 123) e João de Barros menciona a sintáxis ou "construçám das partes" que "segundo difiniçám dos gramáticos, é uma conveniência entre pártes póstas em seus naturáes lugáres, per as quáes vimos em conhiçimento dos nóssos conçeitos" (1540, 1971, p. 349).

Das várias gramáticas compulsadas, conclui-se que sempre a sintaxe está presente, ainda que a concepção que dela se faz possa estar menos ou mais alheada dos moldes em que hoje é concebida.

Interessar-nos-á em seguida olhar atentamente para a línguística moderna e averiguar do âmbito de estudos abrangido por estas duas "velhas" partes da gramática.

\section{A Morfologia e a Sintaxe na Linguística do século XX}

A morfologia, se atendermos à etimologia da palavra, é o estudo das formas. A sintaxe, por seu turno remete-nos para a ordem (do grego "com ordem").

Morfologia e sintaxe sempre dividiram entre si, ao longo da história, o estudo das unidades de primeira articulação, as dicções de Fernão de Oliveira. Usando a terminologia saussuriana, poderíamos dizer que a morfologia se ocupa do estudo do significante, enquanto o estudo do significado é remetido para a sintaxe. A partir de determinada altura (e poderíamos tomar como baliza a obra de J. Reies, Was ist Syntax?, ${ }^{32}$ de 1894), remetem-se para a sintaxe todos os elementos respeitantes à oração, deixando à morfologia o estudo das

32 Seguimos de perto a interpretação de J. Roca-Pons, 1974, p. 99 ss. 
formas gramaticais, não só no seu aspecto externo, mas também no que respeita às suas funções e significações. ${ }^{33}$

$\mathrm{Na}$ Introdução ao estudo da fonologia e morfologia do português, Morais Barbosa refere que basta percorrermos os dicionários de linguística para verificarmos "que vários são os conceitos de morfologia e por conseguinte os campos de estudo que recebem essa designação" (1994, p. 207).

Efectivamente assim é: no Lexique de la terminologie saussurienne, Rudolf Engler apresenta-nos as várias definições encontradas nos escritos do mestre genebrino, das quais destacamos:

science qui traite des unités de sons correspondant à une partie de l'idée, et du groupement de ces unités.[...] Dans les subdivisions de la grammaire au sens traditionnel, la morphologie s'oppose essentiellement à la phonétique, tandis qu'il est difficile de la distinguer de la syntaxe: étude des formes et des fonctions c'est la même chose. (1968, p. 35).

Do apresentado por Josef Vachek, no Dictionnaire de Linguistique de l'École de Prague, seleccionámos: According to the Prague functionalists, morphology is concerned with the analysis of the word, whereas syntax is mainly the analysis of the sentence into its constituents relationships (e.g. subject-predicate, etc. (1970, p. 50). No Glossary of American Technical Linguistic Usage 1925-1950, elaborado por Eric Hamp, encontramos entre outras, a seguinte definição: "Examination of the morphemes of a language and their classification by seriation, is what is usually called morphology. The rest is syntax" (1966, p. 42).

Não encontramos na linguística actual opinião unânime no que respeita às definições de morfologia e sintaxe.

Pela nossa parte seguimos a proposta da teoria funcionalista, elaborada por André Martinet e que concebe a morfologia como o estudo das variantes dos significantes das unidades de primeira articulação, os monemas e sintemas (unidades mínimas significativas).

As dificuldades em elaborar uma definição científica da noção de palavra conduzem-nos a refutar o seu uso para designar entidades linguísticas. Falaremos de monemas, unidades mínimas da primeira articulação, ou seja, signos dotados de um significante e de um significado. Mais adequado será então restringir o uso que possamos fazer da noção de palavra apenas à palavra entendida como unidade gráfica, tendo em conta a ortografia vigente.

33 Para uma revisão aprofundada das distinções entre morfologia e sintaxe, cf. A. Llorente Maldonado (1955). 


\section{Bibliografia}

ÁNGEL ESPARZA, M.; SARMIENTO, R. (org.) (1992) Nebrija, Gramática Castellana. Madrid: Fundación Antonio de Nebrija.

AUROUX, S. et al. (1984) Matériaux pour une histoire des théories linguistiques. Lille: Presses de l’Université de Lille.

AUROUX, S. (dir.) (1992) Histoire des idées linguistiques. Bruxelles: Pierre Mardaga. v. 1, 2.

BARATIN, M. ; DESBORDES, F. (1981) L'analyse linguistique dans L'Antiquité classique - les théories. Paris : Klincksieck.

BARATIN, M. (1989) La naissance de la syntaxe à Rome. Paris: Éditions de Minuit.

BARRETO, M. S. (1970) A convencionalidade do signo linguístico em Aristóteles. Revista de ciências do Homem (Separata), 3, Lourenço Marques, Série A, p. 2-3.

BASSET L.; Perennec, M. (dir.) (1994) Les classes des mots - Traditions et perspectives. Lyon: Presses Universitaires de Lyon.

BLOOMFIELD, L. (1984 [1933]) Language. Chicago: The University of Chicago Press.

BÉCARES BOTAS, V. (1987) Apolónio Discolo- Sintaxis. Madrid: Gredos.

BRAGA, T. (1876) Grammatica portugueza elementar, fundada sobre o methodo historico-comparativo. Porto: Livraria Portugueza e Estrangeira; Rio de Janeiro: A. A. da Cruz Coutinho.

COLOMBAT, B. (dir.) (1988) Les parties du discours. Langages, 92.

DICIONÁRIO DA LÍNGUA PORTUGUESA. (1789) Composto pelo Padre Rafael Bluteau reformado e accrescentado por António de Morais Silva. Lisboa: Officina de Simão Thaddeo Ferreira.

FIGUEIREDO, C. de (1899) Diccionário da Lingua Portuguêsa. Lisboa: Livraria Editora Tavares Cardoso \& Irmão.

HAMP, E. (1966) Glossary of American technical linguistic usage 1925-1950. s.l., s.editora.

HAMP, E.; FRED, H.; ROBERT, A. (1963) Readings in linguistics II. Chicago/ London: The University of Chicago Press.

HJELMSLEV, L. (1976) Principios de gramática general. Madrid: Gredos.

HOLTZ, L. (1981) Donat et la tradition de l'enseignement grammatical: étude sur l'Ars Donati et sa diffusion (IVe-IXe siècle) et édition critique. Paris: Centre National de la Recherche Scientifique. JOOS, M. (ed.) (1966) Readings in linguistics I . 4. ed. Chicago / London: The University of Chicago Press.

LALLOT, J. (1989) La grammaire de Denys le Thrace. Paris: C.N.R.S.

(1996) Apollonius Dyscole et la grammaire alexandrine - conférence/débat? In C. Clairis, Travaux du SELF, IV, p. 39-66.

LLORENTE MALDONADO, A. (1955) Morfología e sintaxis. El problema de la división de la gramática. Granada: Editora Universidad de Granada.

MALMBERG, B. (1991) Histoire de la Linguistique. Paris: PUF.

MARTINET, A. (1986 [1966]) Elementos de linguística geral. Lisboa: Sá da Costa.

MONTEVERDE, E. A. (1833) Elementos de grammatica portugueza, desenvolvidos com a maior clareza possivel para uso das aulas. Lisboa: s/editora.

Nacional. (1886) Manual encyclopedico para uso das escolas de instrução primária. Lisboa: Imprensa 
68 MARÇALO, Maria João. O que é a palavra? Reflexões sobre a herança gramatical greco-latina

MOUNIN, G. (1970) História da Linguística: das origens ao século XX. Porto: Edições Despertar.

NEVES, M. H. de M. (1987) A vertente grega da gramática tradicional. São Paulo: Editora UNESP. PERGNIER, M. (1986) Le mot. Paris: Presses Universitaires de France.

RAMAjO CANO, A. (1987) Las gramáticas de la Lengua Castellana desde Nebrija a Correas. Salamanca: Ediciones Universidad Salamanca.

ROBINS, R. H. (1961) Sintactic analysis. In: HAMP, E.; HOUSEHOLDER, F.; AUSTERLITZ, R. Readings in linguistics II. Chicago / London: The University of Chicago Press.

- (1990) A short history of Linguistics. 3. ed. London/New York: Longman.

ROCA-PONS, J. (1974) Introducción a la gramática. 3. ed. actualizada e ampliada. Madrid: Editorial Teide.

SWIGGERS, P.; VAN HOECKE, W. (dir.) (1986) Mots et parties du discours. Leuven-Paris: Peeters.

VACHEK, J. (1964) Dictionnaire de linguistique de l'École de Prague. Utrecht / Anvers: Spectrum. VIEIRA, Frei D. (1872) Grande dicionário portuguez on Thesouro da Lingua Portugueza. Edição revista e aumentada. Porto: Editores Ernesto Chardron e Bartholomeu de Moraes.

ABSTRACT: In this paper we analyze the inherited ideas about what a Word is, in terms of linguistic description, following the greco-roman tradition. We analyze also some linguistic ideas of authors from XIX-XX century (Vendryès, Saussure) and we trace the way the first Portuguese grammars handled this question (João de Barros, Melo Bacelar, Lobato).

KEYWORDS: Linguistic concepts; word; morphology; syntax; Portuguese. 